\title{
TEACHING NON-FICTION TRANSLATION: THE SYSTEM OF EXERCISES AND TASKS
}

\author{
Leonid Chernovaty, \\ V.N.Karazin Kharkiv National University, Kharkiv, Ukraine \\ leonid.m.chernovaty@meta.ua \\ Natalia Kovalchuk, \\ V.N.Karazin Kharkiv National University, Kharkiv, Ukraine \\ kovalnatalya@bigmir.net
}

\begin{abstract}
Basing on the analysis of the general system of exercises and tasks for translator/interpreter training, the authors offer a threecomponent system of exercises and tasks for teaching non-fiction translation. The components discrimination is based upon their aims, which fall into one of the three categories. The first one is related to the acquisition of skills and subskills, which are required for the translation process, but do not involve translation proper. The second category includes the translation actions and operations that can be automatised, while the third one incorporates translation skills, which are based on the actions and operations of the first two categories. Taking into account the said discrimination, the authors suggest a system composed of three subsystems: (1) preparatory exercises, (2) those intended for the translation automatic components formation, and (3) for the development of translation skills. The authors offer a list of skills and subskills required at each stage of the translation process (the source text analysis, the translation proper and the target text editing), as well as describe the content of groups, types and subtypes of exercises within each subsystem. The prospects of further research are outlined.
\end{abstract}

Keywords: exercises and tasks; groups, types and subtypes of exercises; translator training; system; subsystem; skills and subskills; translation.

\section{Introduction}

At the previous stage of our research into the problems of translator's competence development (Chernovaty, 2018) we have offered a general system of exercises and tasks for translator/interpreter training, which can provide a basis for the development of similar systems related to each type of translation or interpreting. That is, we may talk about the system of exercises and tasks for teaching interpreting, on the one hand, and for teaching (written) translation, on the other. Each of those systems, in their turn, may be subdivided into the corresponding subsystems, e.g. for teaching sight, consecutive or simultaneous interpreting, or for teaching equivalent or heterovalent translation.

This paper is limited to the consideration of the system of exercises and tasks for teaching non-fiction equivalent translation (ET), which is viewed as a full translation of the source text (ST) in contrast to its heterovalent (précis) variety, where the target text (TT) provides only a gist of the ST.

The issue of exercises and tasks for translator training has been touched upon in a number of papers (Nebot, 2008; Kenny, 2008; Calvo, 2015; Motta, 2016; Bowker \& McBride, 2017; Li, 2017) and monographs (see, for example, Gile, 2009). However, in spite of the undoubted value of exercises and tasks suggested in the said sources, it seems that they deal rather with a list of them than with a systemic approach. The one, from which those exercises and tasks would naturally fit into an appropriate slot of the translator training process, and which may provide a sound basis for the development of sets of exercises and tasks required by a particular teacher in a particular segment of the said process, taking into account the specifics of the particular educational settings. Consequently, the problem of the principles of the system of exercises and tasks, whether for teaching translation/interpreting in general or for their specific types, seems to be worth researching because of its importance for the corresponding experimental studies, as well as for the translator training efficiency.

Thus, the aim of this paper is (taking into account the principles of the general system of exercises and tasks for translator/interpreter training (Chernovaty, 2018)), to offer a similar system for ET teaching with the purpose of providing a firm basis for the development of sets of exercises and tasks for any specific stage of the teaching process.

To achieve this aim, we had accomplish a number of objectives: (1) to find out the specifics of ET as an object of teaching; (2) to establish the skills involved in the ET process; (3) to identify the content of exercises and tasks at each level (groups, types and subtypes) of the system's hierarchical structure, as well

Chernovaty, L.\& Kovalchuk, N. (2019). Teaching non-fiction translation: the system of exercises and tasks. Advanced Education, 12, 5-11. DOI: $10.20535 / 2410-8286.155535$ 
as the correlation of them; (4) to make assumptions concerning the mode the suggested system could be used in devising the corresponding sets of exercises and tasks.

\section{Method}

\section{The basic notions}

Within this and other related research (see Chernovaty, 2018), we use the term 'exercise' only concerning those tasks whose aim is to develop automatised actions, i.e. which involve exercising (repetition of a certain action to make it automatic). Because no activity, including translation, can be reduced exclusively to automatised actions, but requires the development of the corresponding skills (ability to purposefully combine available automatised operations in conducting that activity), the term 'task' is reserved for the latter case. Thus, it explains the word combination 'a system of exercises and tasks' used in this paper.

The general system of exercises and tasks for translator/interpreter training (see Chernovaty, 2018 for detail) is based on the three subsystems, which are universal for any other such system related to any type of translation or interpreting.

The first subsystem incorporates preparatory exercises and tasks intended for the development of skills and automatised subskills, which are necessary for translating and/or interpreting, but do not involve any of them. The examples may include drawing notional schemes of a particular sphere for the purpose of the subject knowledge acquisition, making presentations on a specific topic for the same aim, memory training, use of ideographic symbols to memorise the ST content, the multi-purpose (stylistic, terminological, etc.) ST analysis, the monolingual ST compression and paraphrasing (modulation), etc.

The second subsystem includes exercises designed for the development of automatised actions involved in the translation process. Here the students, through the repetition of one or several translation actions, transform them into operations, which would be required in the tasks of the third subsystem. The aim of the latter is to develop translation skills in the conditions simulating the real-life translation situations as closely as possible.

The exercises and tasks of each of the three subsystems are organised hierarchically, falling into groups, types and subtypes. The top-level groups of exercises are intended for the acquisition of relatively complex actions. The latter incorporate a number of simpler actions that have been automatised within the lower-level types of exercises. The lowest-rank subtypes of exercises are meant for the acquisition of the constituent operations.

\section{ET stages and skills}

ET falls into three discrete stages: (1) the ST analysis; (2) the ST translation; (3) the TT editing. Each stage involves a specific set of skills and subskills.

According to our research (Chernovaty, 2013, pp.107-198), the first stage requires the ability to understand the ST taking into account the norms of the native speakers' linguistic and paralingustic behaviour; to identify the types of STs; to analyse the factors that may have an impact on the translation (the ST author's intention, the circumstances of the ST creation, the specifics of the target audience, etc.); to recognise the key elements in the ST; to identify the ST potential translation problems; to assess the possible ways to solve them.

The (sub)skills needed for the TT generation include, among others, the abilities to identify the meaning of unknown words in the ST, to search for the target language lexemes rendering the meanings of the ST, to coin new terms in the target language, to use external information resources, to avoid the word-for-word translation, to maintain the selected translation strategy, to preserve the ST thema-rhematic perspective in the $\mathrm{TT}$, to choose the required genre and the appropriate language means, to select the proper translation techniques, to create multiple TT versions of the same ST, to analyse and screen the intermediate TT variants, to adapt the TT following the consideration of the divergence between the ST author and the target audience, to solve the translation problems.

The final stage requires the following skills: to edit the TT, to choose its best variant, to see the TT drawbacks and to overcome them according to the selected translation strategy, to use the appropriate TT layout in accordance with the client's requirements, to classify errors and mistakes, to carry out the justifiable criticism and assessment of the TT, to make an efficient use of external information resources. 


\section{Results and Discussion}

Taking into account the enumerated (sub)skills, as well as the general system of exercises and tasks for translator/interpreter training (Chernovaty, 2018), the hierarchical structure of the system of exercises and tasks for ET teaching may be represented in the following way (see Fig.1).

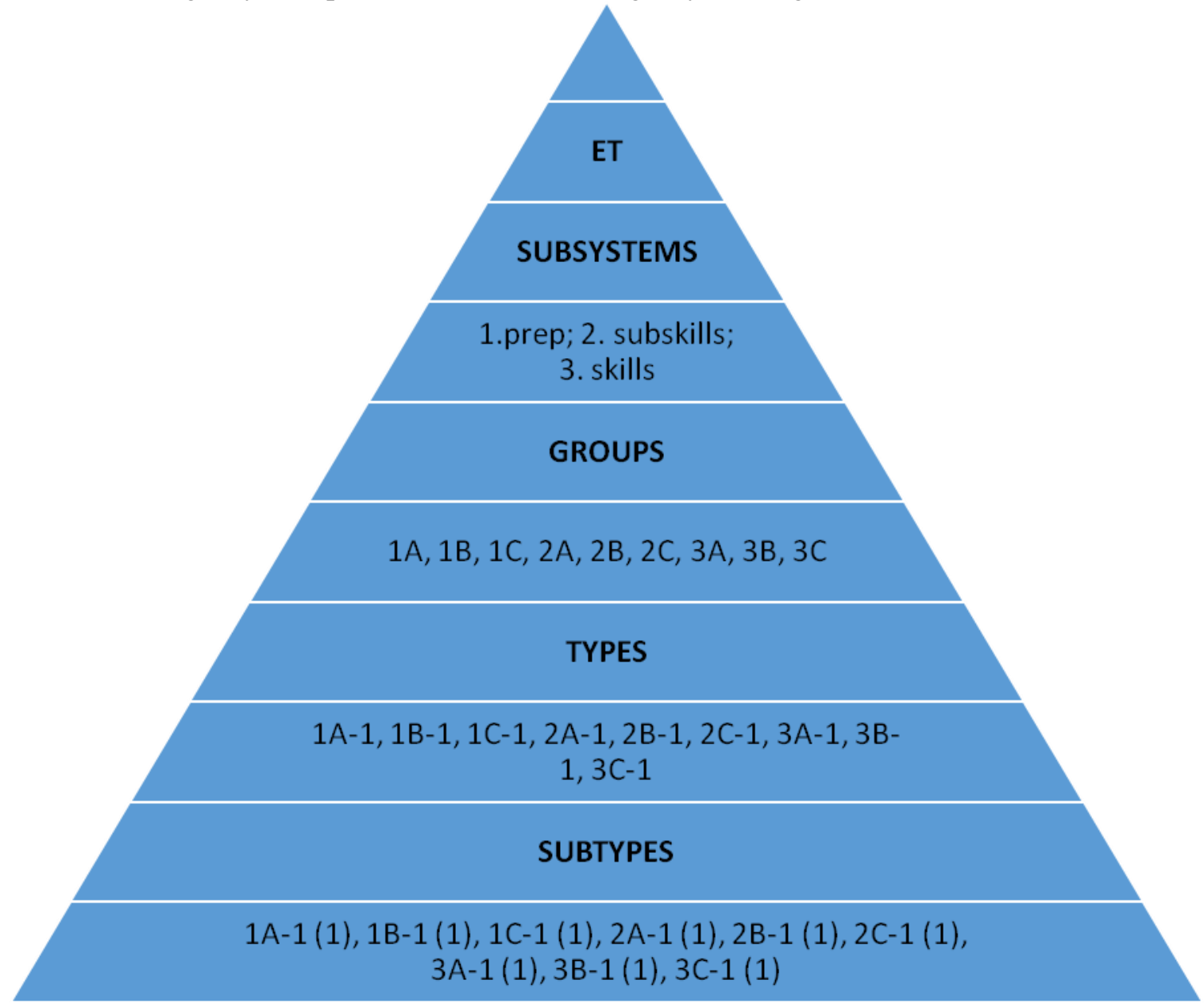

Fig 1. The system of exercises and tasks for teaching equivalent translation

Legend: ET - equivalent (written) translation, prep - preparatory exercises and tasks, subskills - exercises for the development of automatised subskills, skills - tasks for the development of translation skills, GROUPS - groups of exercises and tasks, TYPES types of exercises and tasks, SUBTYPES - subtypes of exercises and tasks, 1A - group A of exercises (tasks) in the preparatory exercises (tasks) subsystem, 1A-1 - type A1-A exercise of the A-group of exercises (tasks) in the preparatory exercises (tasks) subsystem, 1A-1 (1) - subtype 1A-1 (1) exercise of the A1-A type exercise of the A-group of exercises (tasks) in the preparatory exercises (tasks) subsystem etc.

The first subsystem (preparatory exercises and tasks) contains at least six groups of them. Group 1A, which is intended for the development of orientation ability in the ST, includes a variety of tasks related to the understanding of the ST general topic (type 1A-1), its semantic content (type 1A-2), its author's conceptual programme (type 1A-3), its main and supplementary information (type 1A-4), identification of the ST elements' function (e.g. description etc.) and the language means of its realisation (type 1A-5), recognition of explicit markers to indicate the language units' functions (type 1A-6), as well as of the ST implicatures and making the decision concerning their explication in the TT (type 1A-7).

The aim of the group 1B exercises is to develop the psychological mechanisms of the equivalent (written) translation, such as anticipation, for the purpose of which various exercises may be used (filling in the blanks etc.).

The next three groups of tasks are designed to develop the skills of the ST general analysis required at the first stage of the ET process.

Group 1C includes a range of tasks - to analyse the topical and subtopical structure of the ST (type 1C1), ST genre and function (type 1C-2), potential problems in the TT understanding by the target audience in case the ST has not been adapted (type 1C-3), ST language specifics (type 1C-4), ST textual and structural specifics (type 1C-5), ST translatological type - the correlation of cognitive, operational, emotional and 
aesthetic information in the ST (type 1C-6), The ST translation difficulties (type 1C-7) and the general strategy to overcome them, accompanied by appropriate argumentation (type 1C-8).

Group 1D tasks are based on the application of parallel texts, which are often used in translator training. In one type of tasks (1D-1), the students learn to identify translation techniques employed in the TT. The other type of task (1D-2) uses two TT variants of the same ST. The students are expected to compare them, choose a better variant and explain their choice. The 1D-3 type of task requires the TT quality assessment complete with providing the respective reasoning.

Group 1E tasks are intended for the acquisition or activation of the subject knowledge, which is an essential prerequisite for any efficient non-fiction translation. Here the students prepare notional schemes of a particular sphere (type 1E-1), compile the respective two-language terminological glossaries (type 1E-2) and conduct information mining (type 1E-3). The latter type develops the skills of acquiring additional knowledge and skills in the use of information sources, and may fall into several subtypes: searching for information in the paper (subtype 1E-3 (1)) or electronic (1E-3 (2)) sources, as well as through consulting experts in the field (1E-3 (3)).

Finally, there comes the $1 \mathrm{~F}$ group of exercises and tasks, which involves the skills of the text information processing and includes several types of exercises, such as the ST monolingual compression (type 1F-1), explication of the ST implicit information (type 1F-2) and the ST monolingual paraphrasing (type 1F-3).

It is worth reminding that within the first subsystem, all exercises and tasks are done without translation, and hence they are labelled as 'preparatory'. However, translation is an obligatory component in the remaining two subsystems.

The second subsystem, which is designed for the development of automatised actions required in the translation process, comprises only one group of exercises $(2 \mathrm{~A})$ - for the acquisition of lexical and grammar variation subskills. However, this group is extremely multi-componential and includes at least ten types of exercises.

Type 2A-1, intended for the selection of target language lexical equivalents of the source language lexemes, falls into two subtypes: 2A-1 (1) - the selection of monoequivalents, and 2A-1 (2) - the selection from a number of polyequivalents. Depending on other factors, these subtypes may be further divided into sub-subtypes. For example, the students may select the monoequivalents from paper (2A-1 (1a)) or electronic (2A-1 (1b)) sources, on the basis of contextual guessing (2A-1 (1c)), through the lexical and/or grammatical analysis (2A-1 (1d)) or by means of coining a new term (2A-1 (1e)).

The type 2A-2 exercises, where the students learn to convert the ST, may be also divided into subtypes to develop the subskills of the ST paraphrasing (modulation) (2A-2 (1)), compression (2A-2 (2)), discursive creation (2A-2 (3)), etc.

The purpose of the 2A-3 type of exercises is to develop the students' subskills of lexical transformations. The exercise subtypes within this group are differentiated according to the translation techniques to be acquired. For example, the development of the contextual substitution subskills may take place within the 2A-3 (1) subtype, while the operations of, say, particularisation and generalisation may be acquired in the 2A-3 (2) and 2A-3 (3) subtypes of exercises accordingly.

The acquisition of the subskills related to the combined lexical and grammatical transformations is provided for within the 2A-4 type of exercises. This type, like the previous one, also falls into subtypes according to the specific subskill the exercise focusses on. For example, the students may deal with antonymic (2A-3 (1) subtype of exercise) or descriptive translation (2A-3 (2)), compensation (2A-3 (3)), word addition (linguistic amplification) (2A-3 (4)) or deletion (linguistic compression) (2A-3 (5)), etc.

Grammar transformation operations are automatised in the 2A-5 type of exercises, whereas its subtypes are distinguished according to the specific subskill the exercise is intended for. Thus, the students may carry out the operations of word permutation (transposition) (2A-5 (1) subtype of exercises), morphological substitution (changing parts of speech in the TT as compared with the ST) (2A-5 (2)), or syntactic substitution (changing the clause structure) (2A-5 (3)). Students may also deal with the operations of splitting long ST sentences into shorter TT clauses (2A-5 (4)) or alternatively joining ST clauses into compound sentences in the TT (2A-5 (5)).

In the 2A-6 type of exercises, the students acquire the operations related to rendering phrases and idioms by means of different techniques: subtype 2A-6 (1) - rendering the ST meaning by an identical (both the images and the meaning coincide) phrase in the target language: The pot calls the kettle black - Дорікав горщик чавунові, що чорний); subtype 2A-6 (2) - the use of an equivalent (true idiom, the meaning coincides, but the images do not): The pot calls the kettle black - Сміялася верша із сака, коли й сама така (The fish trap was laughing at the landing net though being actually very similar to it); subtype 2A-6 
(3) - coining a quasi-idiom (artificial idiom, the images are different and the meaning is similar): As good be an addled egg as an idle bird - Людина без діла - іхата дотліла (An idle man - a burned hut).

The 2A-7 type of exercises is intended for the acquisition of various types of calque, which is essentially regarded here as copying the structure of a source language word, word combination or clause in the target language. Thus, the discrimination of the types of calque is based on the linguistic level it is applied at. The calque at the level of a phoneme or grapheme is usually labelled as transcoding, which falls into at least four subtypes: (1) in transcribing, we copy the pronunciation of the source language word (тапаgement - менеджмент); (2) in transliteration, the spelling of the source language word is copied (London-Лондон); (3) mixed transcoding uses both of the said techniques in relation to the same source language word (supercomputer - суперкомп'ютер); (4) adaptive transcoding involves copying the graphic form of the source language word with its simultaneous adaptation to the norms of the target language (discipline - дисципліна).

Calque is also possible at the levels of a morpheme (quasi-paradigm - квазіпарадигма); word combination (general semantics - загальна семантика) and clauses or sentences (Science tends to proceed by means of discovery of new areas of ignorance - «Наука має тенденцію розвиватися шляхом відкриття нових острівків незнання»).

Correspondingly, the 2A-7 type of exercises falls into various subtypes and even sub-subtypes. For example, the 2A-7 (1) subtype, which is designed for calquing at the level of a phoneme or grapheme, includes the following sub-subtypes: 2A-7 (1a) (phoneme-level calque - transcribing), 2A-7 (1b) (graphemelevel calque - transliteration), 2A-7 (1c) (mixed transcoding), 2A-7 (1d) (adaptive transcoding). Other subtypes are intended for the calque application at other levels: 2A-7 (2) - morpheme-level, 2A-7 (3) - word combination-level, 2A-7 (4) - clause/sentence-level.

The 2A-8 type of exercises, where the students learn to render the source language word combinations, subject to the combinatory norms in the target language, may be also divided into various subtypes, depending on the constituent components of the said combinations. For example, students may deal with the adjective-noun word combinations in the 2A-8 (1) subtype of exercises, with noun-noun structures - in the $2 \mathrm{~A}-8$ (2) subtype, etc.

The purpose of the 2A-9 type of exercises is the development of the ability to transfer the meaning marked by various grammar structures depending on their functions. This type of exercises may include a range of their subtypes, such as transferring the meaning of the structures that express probability (2A-9 (1)) or focus on specific information (2A-9 (2). Other subtypes may deal with other components of the whole range of communicative functions (expressing specificity, accomplishment, etc.).

In the 2A-10 type of exercises, the students learn to transfer the meaning expressed by the various source language stylistic devices into the TT. This type may also include various subtypes of exercises, such as those intended for rendering stylistically marked meanings (metaphors, play of words, etc.) - subtype 2A10 (1), standard (2A-10 (2)) and non-standard (2A-10 (3)) stylistic devices, etc.

The third subsystem of exercises for teaching (written) translation is more complicated as compared to its counterpart for teaching interpreting (see Chernovaty 2018). There are a number of reasons for it. First, (written) translation involves a post-translation stage, which requires a number of skills that are completely absent in interpreting, such as the TT editing and handing it in to the client. Second, the TT in (written) translation should meet much more rigorous requirements than in interpreting, which is partially related to the absence of the severe time limitations inherent in the latter.

Thus, the third subsystem incorporates six groups of exercises and tasks. Group 3A is meant for the skills of maintaining the selected translation strategy; group 3B - for adapting the TT, taking into account the nature of the ST implicatures; group 3C - for screening the intermediate TT variants. The tasks of group 3D, where the students learn to overcome ST interference, include several types. For example, the students acquire the skills to get rid of the ST linguistic excessiveness (3D-1 type of exercises), to maintain the principal ST information in the TT (3D-2) or to avoid the unnatural word-for-word translation (3D-3).

Group 3E provides for the improvement of the TT design skills through the integration of their constituents related to conforming to the target language linguistic, stylistic and genre norms (spelling, collocations, conventions of a specific text type, etc.).

The 3F group of exercises is meant for the acquisition of the TT editing skills, which are developed in various types of exercises. The students have to see the difference between the ST and TT (3F-1 type), to perceive and overcome the TT drawbacks (3F-2), to criticise and assess the TT (3F-3), to analyse and edit TT according to the selected translation strategy ( $3 \mathrm{~F}-4)$, to choose the best TT from a number of its available variants (3F-5), to classify errors and mistakes and use this classification for the TT quality assessment (3F6), to employ external information resources in the process of the TT editing (3F-7). 
Finally, in the $3 \mathrm{G}$ group of exercises, the students acquire a number of skills required to hand the TT in to the client. The said skills involve the application of the appropriate TT layout (3G-1), providing convincing argumentation for the choice of the specific translation strategy (3G-2) or a specific TT variant (3G-3).

The division of the suggested system into subsystems is motivated by the general psychological structure of activity, which consists of actions (skills) and operations (subskills) (Rubinstein, 1989). Subskills are automatic components of activity, while skills cannot be automatised in principle. Thus, the content of exercises for the subskills formation is essentially different from that of the tasks to develop skills. The former require a multiple repetition of the same operation under the stereotyped conditions and its artificial isolation from other operations to avoid interference on the part of the latter. In contrast, tasks are intended to develop an ability to solve higher-level problems, which calls for the comprehensive, prompt and simultaneous conduct of the available automatised operations in non-stereotyped situations.

Basing on this division, it is not difficult to identify the subsystem (second or third) a particular type of learning activity belongs to. It is equally easy to recognise the one belonging to the first subsystem by the criterion of the absence of translation in it.

Thus, this system seems to be more practical, as compared with other approaches. In one of those (Monashnenko 2015), the system falls into three subsystems according to the stages of the translation process (the source text analysis, translation proper and the target text editing). This mode of subdivision results in the fact that each subsystem incorporates both the exercises to form subskills and the tasks to develop skills, whose content, as it was mentioned earlier, is radically different. A similar approach (Pasichnyk 2010) with similar consequences omits the notion of subskills altogether, suggesting the development of several groups of skills (the source text analysis, translation proper, the target text editing and assessment) at the first stage and their improvement - at the second one.

It is not quite clear here how the skills may function in a full-fledged manner without the preliminary formation of the related subskills. Besides, the term improvement looks ambiguous, because if the skill has already been developed, it can hardly be improved, or alternatively its development has not been completed yet at the previous stages.

In all probability, the author has implicitly included the subskills formation into the development of the first-stage skills, but the improper methodological approach to the structuring of the system of exercises caused the ambiguity of both the terminology and the system itself.

\section{Conclusions}

The suggested system of exercises is open in the sense that each of its subsystems (preparatory, and those intended for the development of skills and subskills) may be supplemented with additional groups, types and subtypes of exercises and tasks, depending on the purpose and content of teaching at a certain stage of this process. This system is not intended to be used in its entirety at any particular stage of teaching but rather serves as a basis for selecting exercises and tasks to meet the specific needs at the said stage of translator training.

The mode of this system's application is far from simple and depends on a wide range of factors. The groups, types and subtypes of exercises and tasks, enumerated in this paper, are never used in a linear fashion, i.e. in the sequence, they have been presented here. Moreover, the same applies to the subsystems themselves - it would be wrong to think that preparatory exercises or tasks are always used before the development of any subskills, and the latter always precedes the acquisition of skills. In real teaching, the sequence of the subsystems, groups, types and subtypes may intermix. The features that affect the mode of this system's application involve the stage of training, its purpose and objectives, the students' experience in translation, the available time budget, etc. These and other factors produce a cumulative effect on devising sets of exercises to achieve a specific purpose at a particular stage of training. The study of the said effect seems to be an important task of the translation pedagogy and a promising area of further research.

\section{References:}

Bowker, L. \& McBride, Ch. (2017). Précis-writing as a form of speed training for translation students. The Interpreter and Translator Training, 11 (4). 259-279. https://doi.org/10.1080/1750399X.2017.1359758

Calvo, E. (2015). Scaffolding translation skills through situated translating approaches: progressive and reflexive methods. The Interpreter and Translator Training, 9 (3), 306-222. https://doi.org/10.1080/1750399X.2015.1103107

Chernovaty, L.M. (2013). Metodyka vykladannia perekladu yak spetsialnosti [Methods of University-level Translator Training]. Vinnytsia: Nova Knyha Publ.

Chernovaty, L.M. (2018). Systema vprav i zavdan yak katehoriia metodyky navchannia perekladu [System of exercises and tasks as a category of translator training methodology]. Inozemni movy, 1, 19-26. 
Gile, D. (2009). Basic Concepts and Models for Interpreter and Translator Training. Amsterdam/Philadelphia: John Benjamins Publishing Company.

Kenny, M.A. (2008). Discussion, Cooperation, Collaboration. The Impact of Task Structure on Student Interaction in a Web-based Translation Exercise Module. The Interpreter and Translator Training, 2(2). 139-164. https://doi.org/10.1080/1750399X.2008.10798771

Li, L. (2017). Training undergraduate translators: a consciousness-raising approach. The Interpreter and Translator Training, 11 (4). 245-258. https://doi.org/10.1080/1750399X.2017.1359757

Monashnenko, A.M. (2015). Obhruntuvannia systemy vprav dlia navchannia maibutnikh filolohiv dvostoronnioho perekladu v ahrarnii haluzi (Substantiation of the system of exercises for teaching bilateral translation in the sphere of agriculture to future philologists). Pedahohica formuvannia tvorchoi osobystosti u vyshchii i zahalnoosvitnii shkolakh, 44 (97), 213-219.

Motta, M. (2016). A blended learning environment based on the principles of deliberate practice for the acquisition of interpreting skills. The Interpreter and Translator Training, 10 (1), 133-149. https://doi.org/10.1080/1750399X.2016.1154347

Nebot, E.M. (2008). Corpus-based Activities in Legal Translator Training. The Interpreter and Translator Training, 2 (2), $221-252$. https://doi.org/10.1080/1750399X.2008.10798775

Pasichnyk, T.D. (2010). Pidsystema vprav dlia navchannya studentiv movnykh vyshchykh navchalnykh zakladiv pysemnoho perekladu komerciinykh lystiv [Subsystem of exercises to teach business correspondence translation to students majoring in foreign languages]. Visnyk Kharkivskoho natsionalnoho universytetu imeni V.N.Karazina. Seriia: Romano-hermanska filolohiia. Metodyka vykladannia inozemnykh mov, 62, 190-200.

Rubinstein, S.L. (1989). Osnovy Obshchei Psikhologii [Basics of General Psychology]. Moscow: Pedagogica.

Received: January 31, 2019 Accepted: February 15, 2019 